\title{
Essential palatal tremor
}

\author{
Amlan Kusum Datta 지, ${ }^{1}$ Uddalak Chakraborty 다, ${ }^{1}$ Atanu Chandra 다, ${ }^{2}$ \\ Jasodhara Chaudhuri ${ }^{1}$
}

${ }^{1}$ Neurology, Institute of Postgraduate Medical Education and Research Bangur Institute of Neurology, Kolkata, West Bengal, India

2Internal Medicine, RG Kar Medical College and Hospital, Kolkata, West Bengal, India

\section{Correspondence to} Dr Atanu Chandra; chandraatanu123@gmail.com

Accepted 30 November 2021

\section{DESCRIPTION}

A 30-year-old man, without any preexisting comorbidities, presented to us with a longstanding complaint of being able to perceive a 'click' in his ears. He found it increasingly difficult to concentrate on tasks. He did not have any other accompanying symptoms such as ataxia or vertigo. He had several ear, nose and throat (ENT) consultations where he was prescribed agents for vertigo and tinnitus but in vain. Brain imaging as well as brainstem auditory evoked response (BAER) tests were unfruitful. Examination of the palate revealed a rhythmic, symmetrical, vertical and oscillating movement of the soft palate at a frequency of 30-50 clicks/min, which produced a clicking sound each time (video 1). It was said to worsen with stress. The movement was not voluntarily suppressible and there were no accompanying signs of brainstem or cranial nerve dysfunction. As per his spouse, the 'click' was audible even while he was asleep. Considering normal neurological examination and imaging findings, a diagnosis of essential palatal tremor (EPT) was made. He was successfully treated with oral clonazepam $(2 \mathrm{mg} /$ day). The patient refused to take botulinum toxin injection. He was followed up for next 6 months during which he showed partial resurgence of the tremor as the medication was tapered, which necessitated resumption of previous doses of clonazepam

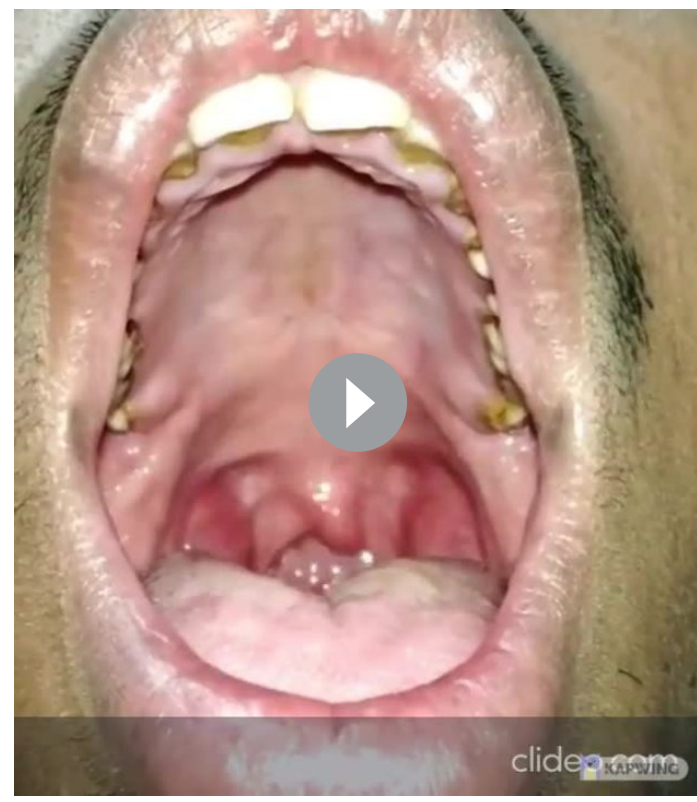

Video 1 Rhythmic, symmetrical, vertical and oscillating movement of the soft palate at a frequency of 30-50 clicks/min producing a clicking sound each time.

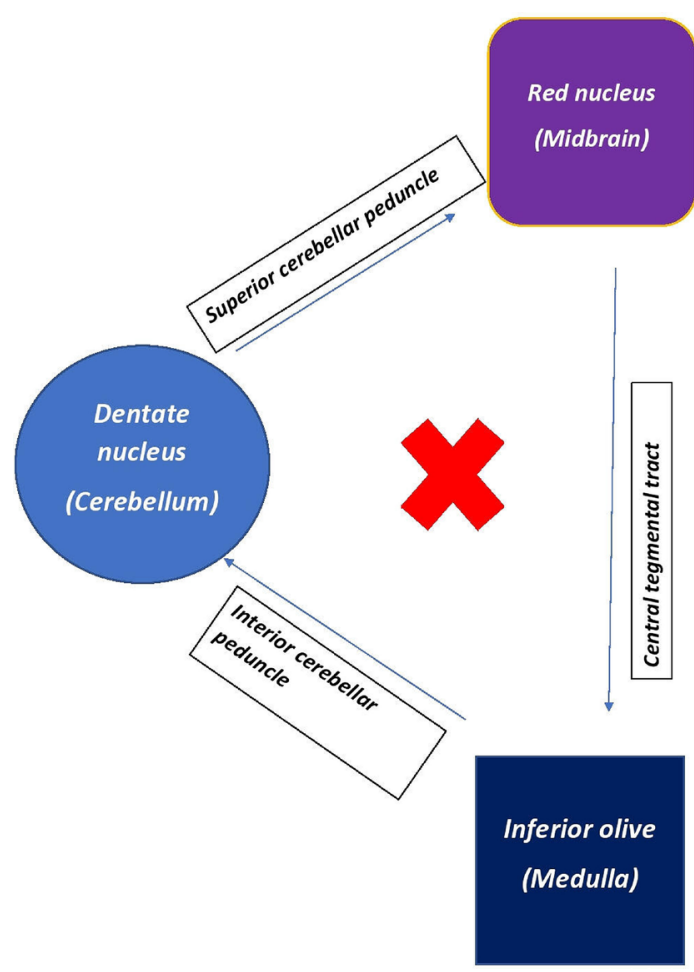

Figure 1 Schematic representation of the hypothetical Gullain-Mollaret triangle. projections from the dentate nucleus of cerebellum pass via the superior cerebellar peduncle, to the contralateral red nucleus and via the central tegmental tract, in the paramedian pontine tegmentum lateral to the medial longitudinal fasciculus, to synapse with the interior olive in the medulla. olivary dentate fibres ascend by the inferior cerebellar peduncle. ' $x$ ' indicates site of lesion anywhere within the hypothetical triangle.

along with addition of a new centrally acting agent in sodium valproate $(400 \mathrm{mg} /$ day).

Palatal tremor is an uncommon hyperkinetic movement disorder comprising rhythmic oscillations of the soft palate. Owing to its rhythmicity, it was classified as a tremor as opposed to earlier label as a myoclonus, in the First International Congress of Movement Disorders in $1990 .^{1}$ Subsequently recognised as two types, symptomatic palatal tremor (SPT) and essential palatal tremor (EPT), by Deuschl et al in 1990; there are important clinical and pathophysiological differences between the two. ${ }^{2}$ Unlike SPT, where clicks are rarely present and associated with neurological deficits like dysarthria and nystagmus, palatal movements and ear clicks are the sole manifestations of EPT. The latter is produced by contraction of the tensor veli-palatini, causing sudden opening and closing of the 
eustachian tube. ${ }^{2}$ The site of lesion in case of SPT is postulated to be the Guillain-Mollaret triangle (figure 1), comprising the dentate nucleus, red nucleus and the inferior olivary nucleus. ${ }^{3}$ Lesions anywhere in the dentato-rubro-olivary pathway cause the olive to get disinhibited resulting in compensatory hypertrophy and synchronous firing of its neurons. ${ }^{4}$ These signals are relayed to the cerebellar cortex via climbing fibres resulting in oscillations. Pathophysiology of EPT, on the other hand, is obscure. As per Pearce, a supranuclear insult to the striatum or rostral brainstem resulting in disinhibition of olivary nucleus may be at play. ${ }^{5}$ Although a functional origin has rarely been suggested owing to occasional suppressibility and distractability, persistence during sleep ruled out such a possibility in the present case. ${ }^{6}$

\section{Patient's perspective}

I was distressed with this clicking sound and was shocked to see my palate in mirror. I rushed to my family physician and he referred me to the neurologist, who consoled me and treated me.

\section{Learning points}

Palatal tremor is a rhythmic oscillation of the soft palate, which even persists during sleep.

- Essential palatal tremor (EPT) is produced due to contraction of tensor veli-palatini, whereas symptomatic palatal tremor (SPT) is attributed to lesion of the Guillain-Mollaret triangle.

- EPT is accompanied by the characteristic audible click which is rare in SPT.
Contributors AKD drafted the initial manuscript and managed the patient. UC, $A C$ and $J C$ helped in documenting necessary investigations and capturing the video. All the authors contributed to the conception, critical revision of content and final approval of manuscript. All authors are in agreement to be accountable for all aspects of the work in ensuring that questions related to the accuracy or integrity of any part of the work are appropriately investigated and resolved.

Funding The authors have not declared a specific grant for this research from any funding agency in the public, commercial or not-for-profit sectors.

Competing interests None declared.

Patient consent for publication Consent obtained directly from patient(s)

Provenance and peer review Not commissioned; externally peer reviewed.

Case reports provide a valuable learning resource for the scientific community and can indicate areas of interest for future research. They should not be used in isolation to guide treatment choices or public health policy.

\section{ORCID iDs}

Amlan Kusum Datta http://orcid.org/0000-0001-6232-0921

Uddalak Chakraborty http://orcid.org/0000-0002-1691-6289

Atanu Chandra http://orcid.org/0000-0002-3809-8926

\section{REFERENCES}

1 Zadikoff $C$, Lang AE, Klein C. The 'essentials' of essential palatal tremor: a reappraisal of the nosology. Brain 2006;129:832-40.

2 Deuschl G, Toro C, Hallett M. Symptomatic and essential palatal tremor. 2. differences of palatal movements. Mov Disord 1994a;9:676-8.

3 Gerace C, Fele MR, Luna R, et al. Bilateral hypertrophic olivary degeneration. J Neurol Neurosurg Psychiatry 2006;77:73-6.

4 Mugnaini E, Nelson BJ. Corticotropin-releasing factor (CRF) in the olivo-cerebellar

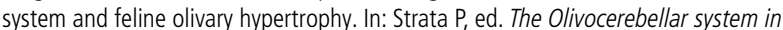
motor control. Berlin: Springer, 1989: pp 187-97.

5 Pearce JMS. Palatal myoclonus (syn. palatal tremor). Eur Neurol 2008;60:312-5.

6 Shikino K, Sato R, Hanazawa N, et al. Chronic clicking tinnitus due to palatal tremor: essential or secondary? Lancet 2021;397:e16.

Copyright 2021 BMJ Publishing Group. All rights reserved. For permission to reuse any of this content visit https://www.bmj.com/company/products-services/rights-and-licensing/permissions/

BMJ Case Report Fellows may re-use this article for personal use and teaching without any further permission.

Become a Fellow of BMJ Case Reports today and you can:

- Submit as many cases as you like

- Enjoy fast sympathetic peer review and rapid publication of accepted articles

- Access all the published articles

- Re-use any of the published material for personal use and teaching without further permission

Customer Service

If you have any further queries about your subscription, please contact our customer services team on +44 (0) 2071111105 or via email at support@bmj.com.

Visit casereports.bmj.com for more articles like this and to become a Fellow 